\title{
Espectrofonias no teatro de Nathalie Sarraute
}

Diego Reis

UFRJ

\begin{abstract}
Resumo
Este ensaio busca analisar de que modo parte do teatro de Nathalie Sarraute pode ser lido como uma espectropoética, isto é, concebido como modo de trabalhar o elemento espectral em suas composiçóes via procedimentos sonoros específicos. Pautadas pela fragmentação sonora, pela polifonia, pela duplicação vocal e figural, as peças de Sarraute teriam como traço comum a ênfase na dimensão auditiva e no universo acústico das operaçôes características de meios sonoros, o que resultaria na criação de zonas de tensão entre temporalidade e espacialidade, matéria sonora das palavras e imagem. Para além da camada semântica, aqui a voz é pensada não apenas com a força de choque de um objeto material, mas também como o lugar de uma ausência que, nela, se transforma em presença. Estas espectropoéticas se configurariam então como exercícios de experimentação vocal e de escuta marcados por traço lacunar, por reduplicações e ressonâncias que caracterizariam a indeterminação da ausência-presença como procedimento formal privilegiado desta dramaturgia.

Palavras-chave: Nathalie Sarraute; Dramaturgia; Poéticas da Cena.
\end{abstract}

\begin{abstract}
This essay aims to analyze how part of the theater of Nathalie Sarraute can be read as a "spectropoetic", that is, conceived as a way of working the spectral element in its compositions by means of sound procedure. Guided by sonorous fragmentation, polyphony, vocal and figural duplication, Sarraute's pieces would have as a common feature the emphasis on the auditory dimension and on the acoustic universe of the operations characteristics of sound media, which would result in the creation of zones of tension between temporality and spatiality, sound matter of words and image. Beyond the semantic layer, the voice is thought not only through of the shock force of a material object, but also as the place of an absence that in it becomes a presence. These "spectropoetics" then would be configured as vocal experimentations and listening exercises marked by a lacunar trait, by reduplications and resonances that would characterize the indetermination of absence-presence as a privileged formal procedure of this dramaturgy.
\end{abstract}

Keywords: Nathalie Sarraute; Dramaturgy; Poetics of the scene. 
Escuta! O que é que ressoa?

- É um corpo sonoro.

- Mas qual? Uma corda, um metal, ou meu próprio corpo?

- Escuta: é uma pele esticada sobre uma câmara de ressonância, e que um outro golpeia ou dedilha, fazendo-te ressoar segundo o teu timbre e ao seu ritmo.

\section{Seria a própria escrita sonora?}

J.-L. Nancy, À escuta
1 RYKNER, A.; RYNGAERT, J-P.

Conversação, 2012, p. 59.

É com o apelo à escuta que muitos dos textos de Nathalie Sarraute se iniciam. A uma escuta ativa que convida o leitor-ouvinte a um mergulho incerto na frequência de emissôes em descompasso, de ruídos e de ressonâncias não de personagens, mas de corpos sonoros em tensão. Daí a forte sensação de se tratar de uma cena fora de sintonia, na qual cada corpo emissor amplifica seus sinais sonoros e parece se chocar com os demais, sobretudo aqueles do receptor, na impossibilidade de acesso às linhas espectrais de uma fala invadida por prosódia, intensidade, duração e altura díspares.

Se não são fortuitos os sinais não captados nesta dramaturgia, não se trata, por outro lado, de um choque entre forças antagônicas ou de mero efeito destinado a sublinhar a impossibilidade da comunicação, como poderia parecer à primeira vista. Isto porque os trabalhos dramatúrgicos de Sarraute são realizados a partir de uma dissimetria inicial entre emissor e receptor, pautada pelo apagamento de alguns signos e pela impossibilidade de se distanciar do significante sonoro. Quer dizer, esta dissimetria não é insuflada por um debate retórico entre personagens, com argumentos e contra-argumentos encadeados, pois não há necessariamente diferentes pontos de vista em disputa. Tudo se passa como se uma "peça de conversação" se desenrolasse com suas falas anódinas e os automatismos do discurso, cuja resultante é a sensação de uma forma dramática "aberta", já que:

\footnotetext{
conversar também significa às vezes escapar da influência da situação dramática, eximir a fala de boa parte de suas obrigaçôes de informaçáo na direçáo do leitor ou do espectador, bem como tornar o intercâmbio ao mesmo tempo mais flexível e enigmático. ${ }^{1}$
}

Disto resulta a incorporação dos silêncios, das hesitaçôes, das reticências e de uma série de procedimentos característicos da oralidade, com o consequente deslocamento do privilégio concedido à situação dramática em 
2 No ensaio "Le gant retourné" [A luva revirada], publicado em 1975 nos Cahiers Renaud-Barrault (n ${ }^{\circ} 89$, p. 70-7), Sarraute escreve que a peça foi escrita em 1964 por conta de uma encomenda da Radio alemã de Stuttgart. Ela seria levada à cena pela primeira vez em janeiro de 1967, dirigida por JeanLouis Barrault, na inauguração do Théâtre Petit Odéon em Paris.

3 SARRAUTE, N. Le silence. 1978, p. 151. Tradução nossa.

4 JOLLY, G.; SILVA, A, M. da. Voz, 2012, p.187.

5 RYNGAERT, J-P. Personagem (crise do). 2102, p. 137. detrimento dos conjuntos sonoros que funcionam, sobretudo, como partituras-para-voz. De onde se depreende dos textos uma verdadeira orquestração de vozes que se desdobram, de timbres e ritmos multiplicados, em contínua diferenciação, aceleração ou rarefação em diversas peças. Como H.1, H.2, H.3 e F de Elle est là, de 1978, que retornariam simetricamente em Pour un oui ou pour ou non, de 1982; ou ainda, nos "eles" e "elas" múltiplos de C'est beau, de 1978, ou de Isma - ou ce qui s'appelle rien, de 1970. E que, no entanto, mesmo pluralizados nestas séries, parecem reafirmar o repertório vocal prosaico e coletivo, e não falas crípticas a que se necessitariam restituir qualquer intencionalidade comunicativa encoberta.

Trata-se de forma dramatúrgica que toma da operação de escuta e do universo radiofônico o seu modo de estruturação. O que parece justificar os inícios algo abruptos das peças, como se a emissão começasse subitamente ao deslizar do toque de algum ouvinte distraído. Veja-se, para citar um exemplo, as primeiras linhas de $O$ Silêncio, ${ }^{2}$ peça radiofônica publicada em 1967, que principia por um pedido da voz F.1: "Conta... Foi táo bonito. Você conta táo bem...”. Seguido da recusa de seu primeiro interlocutor, H.1: "Não, por favor..."3 E de uma série de outras vozes sobrepostas e intermitentes que se dirigem a H.1 como suplicantes por uma narrativa que não vem. Aqui, é o silêncio que se erige como objeto de todas as falas proferidas na peça e, paradoxalmente, como ameaça permanente. Um silêncio impossível, que ganha lugar apenas nas lacunas discursivas e nas reticências, supressôes e omissóes que estruturam o texto. E que desafiam o ouvinte-leitor de saída, por meio do "silêncio semântico" que obstaculiza a compreensão do tema em discussão pelos personagens.

Mas se, de um lado, o estatuto da voz neste teatro se liga à materialidade sonora de um corpo que emerge da performance vocal, de outro lado, é evidente também a dissolução da personagem, com mínimos traços de subjetividade e completamente ancorada nos microconflitos do universo acústico. Como se estas "entidades" dramáticas fossem nada além de sons e toda agonística não fosse senão o reflexo disso: de um fluxo sonoro-discursivo estilhaçado pelo silêncio, pelos brancos e pelo "grão da voz" teatral. Esse fluxo marca as dissenções e a fricção da matéria que não se apazigua ou se deixa capturar pela homogeneização vocal e que, por isso, sublinha modos de locução problemáticos. $\mathrm{O}$ "estilhaçamento do sujeito falante" ${ }^{4}$ resulta, assim, da proliferação de vozes e de enunciadores-siglas, em sucessão contínua, que redefinem o personagem "no desvão entre a voz que fala e os discursos que ela pronuncia”. 5

É neste processo, pois, que se expóem os traços fundamentais de formalização e de encenação da fala no teatro de Sarraute, por meio dos quais os recursos expressivos do rádio são experimentados. E não apenas com os 
registros e a entonação diversos que caracterizam a expressão radiofônica, mas igualmente como "rastro vocal gravado" divergentes e simultâneas, que se veem ora quase justapostas, ora de fato sobrepostas, em atrito, em interferência direta, multiplicando ainda os destinatários e os endereçamentos. Às vezes eles são meramente supostos pelas vozes em diálogo, como em Elle est là, ${ }^{7}$ peça na qual há uma disputa entre três interlocutores - H.1, H.2 e H.3 -, que colocam em questão o gesto duplo e flutuante de guardar o silêncio (omissão voluntária) e o convencimento a todo custo (enunciação permanente de uma ideia) a que F é submetida. E que o próprio título da peça remarca pelas ambiguidades do pronome pessoal e do advérbio de lugar, dêiticos que se convertem tanto em "ela" e na "ideia" a que se pretende fulminar quanto em um "aqui" e "lá" simultâneos que as tornam onipresentes.

Não surpreende que, ironicamente, no decorrer da peça não sejam expostas as ideias em disputa. Esta obliteração deixa entrever as estratégias argumentativas nos atos de linguagem e os "efeitos de voz" empregados pelos enunciadores - em tom de "jargão" - das citaçôes ou dos subentendidos. A ênfase conferida à oralidade do texto é reiterada pela aparência de conversação entre as figuras, que se mostram obstinadas na destruição da ideia intolerável de F, que, por sua vez, "não faz mais que escapar. Não pede senão guardar o silêncio". ${ }^{8}$

Este silêncio insuportável de uma entidade dramática indefinida e esquiva, que desliza às estratégias argumentativas, é compreendido então como ameaça. Extirpá-lo demandará um gesto não à toa concebido como crime, de tal modo que H.2 vocifera a F que ela será "forçada a escutar", intimidação a que $\mathrm{F}$ responde apertando os ouvidos com as mãos. Esta luta entre a escuta forçada e a omissão silenciosa, mas discordante, se trava, de fato, não no campo das ideias, mas da emissão e da recepção.

É o que encontramos de modo similar em $O$ silêncio, peça na qual um grupo de vozes anônimas pressionam $\mathrm{H} .1$ a terminar a descrição de sua casa da infância. Ao que esta voz reage, entre suplicante e indignada, para que se pare, diante da impossibilidade de resguardar o silêncio e um espaço mínimo de autenticidade fora da massa subordinada ao trânsito comunicativo. O receio de ser tomado pela palavra coletiva de um grupo anônimo e acossado pelas vozes que o interpelam reiteradamente é o que lança H.1 em uma experiência de inautenticidade, tal qual um autômato, expondo os clichês de que faz uso, a trivialidade das situaçôes e reforçando o seu próprio anonimato, fruto de uma voz comum que parece antecedê-lo. Deslocada do grupo, esta voz solitária, H.1, que não chega a constituir-se plenamente em sua individualidade, só se afirma pela reação diante da provocação que desordena a imagem lírica criada por H.1 para si mesmo. É aí que as sete vozes
6 SÜSSEKIND, Flora. Coro, contrários, massa: A experiência tropicalista e o Brasil de fins dos anos 60. 2005, p. 56.

7 SARRAUTE, Nathalie. Elle est là. 1978, p. 30. Tradução nossa.

8 Ibidem, p. 49. Tradução nossa.

9 Ibidem, p. 40. Tradução nossa. 
10 Idem. Le mensonge. 1978, p. 143. de $O$ silêncio indicam o desdobramento potencial de uma única voz: esta de H.1, metamorfoseada, uniforme e comum, menos voz interior do que fruto dos tropos que costuram a narrativa.

A voz branca que percorre os textos de Sarraute e ressoa no timbre de vocalizações quase maquínicas reitera fórmulas coletivas e se constitui em suporte do simulacro de jogo acústico por meio do qual os enunciados e as imagens são esvaziados de qualquer densidade para serem assimilados como puro fluxo de fala em repetição. Como revela Pierre em Le mensonge:

Pierre, imitando Simone: Bem, bem, é claro, eu estava jogando/ encenando [jouais]...

Robert: O que você diz?

Pierre, sonhador: Eu repito o que Simone disse com o mesmo sorriso, o mesmo tom... Tento refazê-lo... os mesmos movimentos... Mais longe... Sempre mais longe... ainda mais longe que anteriormente... Lá onde ninguém poderá desalojá-la... E nós jogamos isso para nos divertir, para nos manter sob controle. ${ }^{10}$

O jogo, aqui, funciona como um jogo de linguagem irredutível à designação de objetos isolados. Gesto de fala mimetizado que tornaria a figurar em uma série de outras produçôes da dramaturgia sarrautiana. E que resultaria em um misto de experimento de uma práxis comunicativa problemática e de teste que coloca em questão procedimentos visando a explorar operaçôes de brancura rítmica. "Sempre mais longe", a linguagem do indecidível é escavada por meio de processos sistemáticos de suspensão via reticência, que interrompem fluxos de fala e cravam, no interior dos textos, hesitaçóes comuns ao registro oral. Não raro, indicam uma abertura semântica que, paradoxalmente, resiste à interpretação do leitor por conta de uma fragmentação da linguagem, cujo discurso entrecortado, elíptico, agudiza a descontinuidade sonora. Por isso, a expressão corriqueira dos mal entendidos entre as figuras sonoras, sem reconciliação final, ou mesmo aquilo que, subentendido, revela-se problemático menos pelo conteúdo do que pela forma como é dito.

Não deixa de ser significativa, nesse sentido, a proliferação das metáforas e das chamadas que sugerem uma audição alterada pela língua. O coral de vozes diversas se encontra diante do mutismo de uma voz que se recusa à emissão, como no caso do Jean-Pierre de O Silêncio, para citar apenas um exemplo, e que contrasta os fiapos de espaços íntimos, que ainda restam, à pressão de uma dicção onipresente, neutra e que a tudo devassa.

Salvo quando, na voz anônima de algum personagem, incorporam-se sob a forma da citação trechos mais ou menos conhecidos da literatura 
clássica. Invadido por imagens plagiadas e pelos efeitos superficiais de uma lírica reconhecivel, citações, paródias, repetiçôes, empréstimos, excertos e alusóes que criam, assim, um mosaico referencial que problematiza a espontaneidade das falas. Pois estas se acham minadas pelos usos estratégicos de lugares-comuns segundo a orientação de um lirismo medíocre que só encontra lugar no drama como caricatura ou extravagância. Assim, em Pour un oui ou pour un non, fórmulas prosaicas da poesia de Verlaine são mote de discussão entre H.1 e H.2, haja vista que o primeiro é acusado de falar somente "entre aspas", revelando, uma vez mais, a tensão da inautenticidade de um discurso que se contenta em retomar modelos escolares de distinção pela via da reprodução mecânica de frases de efeito. ${ }^{11}$

Mas não seria somente a questão referencial que estaria em foco nesta peça. Trata-se também da exposição de uma questão de prosódia que define todo o seu andamento, por conta de uma disjunção fônica suspeita:

H.2: Bem... Você me disse há algum tempo... você me disse... quando eu me vangloriava de não sei mais o quê... de não sei mais que sucesso... sim... derrisório... quando eu te falei... você me disse: "É bom... isso..."

H.1: Repita, eu te peço... devo ter ouvido mal.

H.2, tomando coragem: Você me disse: "É bom... isso..." Exatamente com este suspense... este tom...

H.1: Isto não é verdade. Não pode ser isso... não é possível...

H.2: Você vê, eu bem havia dito... por que se preocupar?

H.1: Verdadeiramente não. Isto não é uma piada? Você fala seriamente?

H.2: Sim. Muito. Muito seriamente.

H.1: Escute, diga-me se eu sonho... se eu me engano... Você teria compartilhado um sucesso... que sucesso aliás...

H.2: Oh, pouco importa... um sucesso qualquer...

H.1: E então eu teria dito: "É bom isso?"

H.2, suspira: Não completamente assim... havia entre "É bom" e "isso" um intervalo maior: "É booom....... isso...". Um acento colocado no "bom"... um prolongamento: "booom..." e um suspense [suspens] antes que chegasse "isso"... não é sem importância. ${ }^{12}$

A entonação, o ritmo e a acentuação da linguagem falada se tornam o ponto de ruptura entre os dois personagens, o que teria por consequência inclusive a tentativa de instauraçáo de um inquérito judicial, em nome da garantia da "respeitabilidade" cidadá. O problema do contínuo sonoro e a pressuposta derrisão devido à duração e ao acento prosódico da fala se convertem, entáo, no mote de uma longa conversa no decorrer da qual a divagação tonal de H.2 se opóe ao pragmatismo de H.1. Porque se o emprego de acentos melódicos ou dos tons poéticos, que encantam H.2, se
11 Em O Silêncio, de maneira similar, há uma frase proferida por F.3 atribuída a Balzac em seu romance Louis Lambert que funciona como explicação possível para o silêncio de Jean-Pierre (F.3: "Il y a des gens... leur seule présence paralyse et les voix et les coeurs..."). O recurso à citação literal é novamente empregado na conversa dos personagens. E, lembre-se ainda, o silêncio de Jean-Pierre só é rompido quando H.1 se refere a um suposto livro de arte bizantina, de Labovic. Nesse momento, Jean-Pierre, Monsieur Snob, rompe enfim seu estado de surdez e seu mutismo, ávido pela referência editorial do livro mencionado.

12 SARRAUTE, Nathalie. Pour un oui ou pour un non. 1978, p. 11-12.

13 Ibidem, p. 23.

14 Ibidem, p. 28. 
15 HAUSBEI, K; HEULOT, F. Monólogo. 2012, p. 116. expressa como tentativa de constituição de personalidade meio lírica "meio mistica meio santa", ${ }^{13}$ implicitamente, replica H.1, a distância poética indica a ironia e o desprezo que auratizam o mundo segundo uma perspectiva não apenas contemplativa, mas de superioridade. E, integrada a ela, se introduz, em contrapartida linguística, um tom flutuante, inconsistente e ameaçador ante o qual tudo se coloca em suspensão e se desfaz. Daí a necessidade de "que eu saia de lá o mais rápido possivvel... que eu me reencontre em casa, onde tudo é estável. Sólido" ${ }^{14}$ conforme conclui H.1.

É justamente a estabilidade de uma comunicação resistente à objetivação que está em jogo aqui. E se os discursos são reiteráveis pelas vozes despersonalizadas que os transmitem, elas, as vozes, não estão incólumes às interferências e aos trânsitos problemáticos das inúmeras oralidades em sequência. Os dramas interiores são igualmente marcados pela mediação de vozes que não escapam à articulação ruidosa entre verbo e voz, e que se atritam na superfície modulável do som e da locução estranhamente dessubjetivada. Como se, antes mesmo da enunciação, todas as figuras se colocassem em posição de escuta ampliada de um fato acústico que é anterior ao início das peças.

A ausência, além disso, de qualquer indicação cênica de lugar, nos textos de Sarraute, reforça a ênfase na audibilidade em detrimento da dimensão visual. A paisagem sonora se impóe como única coordenada de um procedimento de orquestração acusmática de vozes, cujas operaçôes de apagamento, de suspenção e de silenciamento (inclusive identitário) parecem recorrer a espectrofonias e a vozes brancas como modo essencial de formalização da dramaturgia sarrautiana.

Pois se as figuras sonoras se desdobram em outras similares, como se de seu próprio eco se constituíssem novas vozes encadeadas, não é difícil, porém, mapear a presença do discurso monológico neste tecido de vozes polifônicas. Como em Elle est là, peça na qual as falas de H.1, H.2 e H.3 parecem fragmentar uma mesma voz dirigida a "ela” (F), que não possui qualquer interesse de intervenção. Esta voz tripartida assinala o estado interior dos corpos sonoros em busca de uma interlocutora espectral, cuja presença-ausência instabiliza as enunciaçôes e inviabiliza as possibilidades de diálogo. A partilha impossível diante da recusa dialógica resulta no monólogo como "último espaço da palavra possível", ${ }^{15}$ ainda que exasperado, descontrolado e fragmentário. $\mathrm{O}$ que náo anula, de outro lado, a indisposição patente à escuta e a reação violenta como meio final de estabelecer vínculo com o outro e demarcar, nesse gesto brutal e impetuoso, a impossibilidade mesma do drama. 
Importa ressaltar que o interlocutor direto nesse caso é sobretudo o ouvinte. É para os seus ouvidos que as massas vocais se direcionam, suspensivas ou conclusivas, em alternância rítmica. Os movimentos de fala, as pausas discursivas e os ecos prosódicos são organizados de modo a supor um ouvinte potencial para o qual as figuras sonoras orientam a emissão. Tratase, portanto, de uma abertura na escrita para a oralidade e para a escuta que confere ao teatro de Sarraute uma materialidade rítmica própria. O endereçamento auditivo sublinha menos o conteúdo dos enunciados ou seu aspecto semântico do que uma vocalização que "atravessa o corpo, emana do corpo, ao mesmo tempo que o corpo emite suas vibraçóes", ${ }^{16}$ segundo assinala Claude Régy, responsável pela direção francesa de três peças de Sarraute: Isma (1973), C'est beau (1975) e Elle est là (1980).

Estas espectropoéticas cênicas, malgrado sua diferença, se configurariam então como exercícios de experimentação vocal e de escuta marcados por traço lacunar, por reduplicaçôes, ressonâncias e espelhamentos que caracterizam a indeterminação da ausência-presença como procedimento formal privilegiado destas dramaturgias. E materializado nas operaçôes de apagamento, nas repetiçóes, nos cancelamentos semânticos e na proliferação de vozes em off ou didascálicas. Além das vocalizações fragmentárias, elípticas, às vezes quase decompostas na situação de enunciação, que dissociam presença cênica e emissão. Daí o estranhamento de uma voz que narra situaçóes de vida dos protagonistas, mas que nunca é deles mesmos, configurando-se como instância exterior que, simultaneamente, se refere a eles e fixa-os na posição de ouvintes.

É aí onde o fantasma não passa de índice, de um traço "entre vida e morte" que "não está jamais presente enquanto tal" senão para "desajustar a identidade a si do presente vivo", ${ }^{17}$ que se inscreve este teatro. Isto porque, por meio da disjunção entre voz e corpo, entre imagem cênica e dicção, afirma um sujeito desidentificado a si mesmo, vestigial, que irrompe no fluxo de uma voz desencarnada e restabelece, continuamente, uma relação de alteridade. A dimensão espectral, evocada pela polifonia das vozes despersonalizadas e pela multiplicação das zonas de ressonância, introduz um princípio geminado na enunciação que condensa a espectralidade no modo de vocalizaçáo dos textos. E isto tanto pela via da voz épica que invade a cena e interrompe a ação - constituindo uma espécie de narrador-voz externo à cena que se desenrola -, quanto pelo recurso à voz acusmatizada, sem o suporte aparente de um enunciador, e não sincronizada com as imagens verbais e visuais. Para além da camada semântica, aqui a voz é pensada não apenas "com a força de choque de um objeto material", mas também como o "lugar de uma ausência que, nela, se transforma em presença". ${ }^{18}$
16 RÉGY, C. Le champ de la voix. La Licorne, 1997, p. 43-51.

17 DERRIDA, Jacques. Espectros de Marx: O Estado da divida, o trabalho do luto e a nova Internacional, 1994, p. 10 et seq. 
18 ZUMTHOR, P. Introdução $\grave{A}$ Poesia Oral, 1997, p. 11.

19 SARRAUTE, N. C'est beau. 1978, p. 75-6. Tradução nossa.

20 Idem. Isma ou ce qui s'appelle rien, 1978, p. 65. Tradução nossa.

21 Ibidem, p. 102.
Deste modo, o espectro sonoro que se delineia no conjunto dos textos dramatúrgicos de Sarraute é estruturado por fontes emissoras cujas vozes simultaneamente anônimas e plurais parecem reverberar no ouvinte duplamente figurado - no plano intraficcional e como audiência do texto. Processo acústico complexo, as vozes fechadas, brancas, graves ou em off se acumulam como registros vocais desarmônicos, com extensão díspar, e "quebrados" pela mudança súbita de timbre.

É o caso de C'est Beau e seu repertório contínuo de vozes que ressoam e silenciam ao longo da conversa entre "ele" e "ela". O título da peça indica já a expressão do interdito que mobiliza a trama sonora entre as figuras, isto é, o que não deve ser dito sob nenhuma hipótese - "É lindo" são palavras que nós não ousamos pronunciar na presença de nosso filho", ${ }^{19}$ confessa "ele". Mas as vozes judicativas e vigilantes das famílias do entorno não deixam de assombrar os personagens, em um trânsito acelerado: Duranton, Herbat, Charrat, cada qual com sua forma discursiva peculiar e marcada por dissonância característica aos rumores. Aos poucos, todas elas se metamorfoseiam em um único conjunto vocal não identificado, o das "vozes diversas", que se dissipam sob a bruma acústica de sua própria impessoalidade. Estas vozes proverbiais que invadem a cena do texto e que retornam com certa frequência nesta dramaturgia não são casuais. Talvez elas funcionem como voz normativa, como o burburinho do comum que, por estranha pressão, coage as figuras decalcadas a uma reintegração, a uma homogeneidade vocal.

É significativo notar o agenciamento levado a cabo por estas vozes indeterminadas e aéreas, engajadas, por vezes, simplesmente em denegrir a imagem de um ausente pela "an-ti-pa-tia" em relação ao modo como pronunciam determinadas palavras. É o que lemos em Isma - ou ce qui s'appelle rien, ${ }^{20}$ comédia pautada pelo emprego dos tropismos e pela oposição entre dois grupos distintos de personagens - "ele" e "ela" versus H.1, H.2 e H.3, e F.1, F.2 e F.3. O combate verbal que se trava ao longo da peça se deve ao fato de os "Dubuit", casal ausente, terem o terrível hábito de pronunciar as palavras em "isme" [ismo], que soam como "isma" ao final. Este traço ínfimo de algo "que se chama nada" se converte, porém, na razão do ódio profundo contra o que fere os ouvidos de maneira atroz. Desconcertante, a brutalidade deste pequeninissimo gesto linguístico, que martela a escuta em seu eco prosódico, causa uma espécie de vertigem, um irredutível sonoro que os vem "assombrar à noite... absurdos... insensíveis"21

A cena do texto é atravessada, portanto, por procedimentos de formalização da voz e da imagem expressos na grafia do fantasmal, bem como nas zonas de tensão entre espacialidades e temporalidades plurais, heterogêneas e anacrônicas. Assim, há uma reelaboração da linguagem, por meio da qual se verifica maior consciência do alcance dos meios (inclusive técnicos, se 
consideramos os recursos radiofônicos), que se reflete na produção dramatúrgica de imagens descontínuas, de vozes internamente dissonantes e na multiplicidade de configuraçóes rítmicas rastreadas nos textos.

Se a dimensão sonora constitui o campo de experimentação privilegiado desta poética, então uma leitura centrada no universo acústico, nas esquematizaçôes rítmicas e em seus diferimentos talvez seja interessante para compreensão do efeito fantasmático que parece emergir dos rastros vocais constituídos como acontecimentos da linguagem. E que introduz, ademais, um eixo de desorientação espaço-temporal patente, como se restasse ainda um vestígio daqueles velhos fantasmas de mãos estendidas arrancados do passado. Só que agora transposta "a irrealidade da coisa para a realidade da linguagem", ${ }^{22}$ e rumo a outra invisibilidade: a da brancura rítmica e do "eco do que não pode parar de falar". ${ }^{23}$

Estas espectrofonias sarrautianas podem ser consideradas escrituras sonoras por meio das quais a escuta parece se configurar como dimensão privilegiada. É do atrito e da tensão entre o traço vocal, o traço figural e o traço gráfico que emerge um phantasmata, um hiato que complexifica os limites entre a cena e suas bordas, entre a camada sintático-semântica e a percepção de sua estrutura rítmico-sonora. E que, como propóe Susan Sontag em $A$ Estética do Silêncio ${ }^{24}$ são capazes de acionar dimensôes de "ininteligibilidade", de "invisibilidade" e de "inaudibilidade" na "materialidade perturbadora" que resta.

O teatro da fala de Sarraute joga com estes deslizamentos sonoros pela proliferação de assonâncias, aliterações, parônimos. Ou mesmo pelos subentendidos causados por silepses, por entonaçôes ou ênfases problemáticas. É desta perspectiva que silabadas, cacoépias, onomatopeias e cacofonias são recursos fônicos que, na escrita sarrautiana, não podem se dissociar do universo acústico em tensão: surpresas são ouvidas como ironia ou sarcasmo; rumores se erigem como interferência ativa ou repercussão ininterrupta; asserções se transmutam em interrogaçôes despropositadas. Como se houvesse um descompasso na respiração por conta de acentos sempre duvidosos, irregulares ou intencionalmente errôneos das palavras. Dissimetria de frequência que talvez aponte para a delimitação de territórios de experimentação vocal no teatro e para uma ampliação do entendimento da caixa cênica (para além da visualidade). Por isso, o sentido adquire valor quase exclusivamente sonoro na cena sarrautiana: o de caixas de ressonância cujos ruídos e perturbaçôes audíveis intensificam espectros sonoro-dramatúrgicos.
22 BLANCHOT, Maurice. $A$ parte do fogo. 1997, p. 315.

23 Idem, O espaço literário. 1987, p. 17.

24 SONTAG, Susan. A Estética do Silêncio. 2015, p.12 et seq. 


\section{Referências}

BLANCHOT, M. A parte do fogo. Tradução de Ana Maria Scherer. Rio de Janeiro: Rocco, 1997.

BLANCHOT, M. O espaço literário. Tradução de Álvaro Cabral. Rio de Janeiro: Rocco, 1987.

DERRIDA, J. Espectros de Marx: o Estado da divida, o trabalho do luto e a nova Internacional. Tradução de Anamaria Skinner. Rio de Janeiro: Relume Dumará, 1994.

HAUSBEI, K.; HEULOT, F. Monólogo. In: SARRAZAC, J-P. (Org.). Léxico do drama moderno e contemporâneo. São Paulo: Cosac Naify, 2012.

JOLLY, G.; SILVA, A. M. da. Voz. In: SARRAZAC, J-P. (Org.). Léxico do drama moderno e contemporâneo. São Paulo: Cosac Naify, 2012.

NANCY, J.-L. À escuta. Tradução de Fernanda Bernardo. Belo Horizonte: Edições Chão da Feira, 2014.

RÉGY, C. Le champ de la voix, entrevue a G. Dessons. La Licorne, v. 1, n. 41, p. 43-51. Poitiers: Université de Poitiers, 1997.

RYNGAERT, J-P. Personagem (crise do). In: SARRAZAC, J-P. (Org.). Léxico do drama moderno e contemporâneo. São Paulo: Cosac Naify, 2012.

RYKNER, A.; RYNGAERT, J-P. Conversação. In: SARRAZAC, J-P. (Org.). Léxico do drama moderno e contemporâneo. São Paulo: Cosac Naify, 2012.

SARRAUTE, N. Théâtre. Paris: Éditions Gallimard, 1978.

SONTAG, S. A. Estética do Silêncio. In: A Vontade Radical. Tradução de João Roberto Martins Filho. São Paulo: Companhia das Letras, 2015, p. 12 et seq.

SÜSSEKIND, F. Coro, contrários, massa: A experiência tropicalista e o Brasil de fins dos anos 60. In: BASUALDO, Carlos. (Org.). Tropicália: Uma revolução na cultura brasileira. São Paulo: Cosac Naify, 2005.

ZUMTHOR, P. Introdução à Poesia Oral. Tradução de Jerusa Pires Ferreira, Maria Lucia Diniz Porchat e Maria Inês de Almeida. São Paulo: Editora Hucitec, 1997.

Submissão: 21/09/2018

Aceite: 07/03/2019

https://doi.org/10.5007/2176-8552.2018n25p84 